\title{
Disadvantaged groups in the labour market
}

\section{SUMMARY}

Employment rates vary among different groups of the population, affected by factors such as age, sex, region, ethnic origin, disability status and level of qualification. Some groups face particular barriers to entering, remaining in and progressing within employment. This article considers the economic activity of groups that are considered to face such barriers and be disadvantaged with respect to opportunities for employment. i he groups within the article are those identified as disadvantaged in the Public Service Agreements (PSAs) agreed by the UK Government in 2007 for the spending period of 2008 to 2011. PSAs set out the key priority outcomes the Government wants to achieve within a spending period. Each PSA is underpinned by a single delivery agreement shared across all contributing policy departments and developed in consultation with delivery partners and frontline workers. The delivery agreements also describe the performance indicators that will be used to measure progress towards each PSA (See Department for Work and Pensions (DWP)).

PSA Delivery Agreement 8 (PSA8) is to 'maximise employment opportunity for all'. One of the performance indicators for this Delivery Agreement is a narrowing of the gap between the employment rates of the following disadvantaged groups and the overall rate for all people:

- disabled people

- lone parents

- ethnic minorities

- people aged 50 and over

- the lowest qualified, and

- those living in the most deprived local authority wards

These groups are defined in more detail in Box 1.

This article looks at the employment rates of these groups from the earliest available data through to the end of 2009 , commenting on changes during the recession. The time series for the groups start at different points, as different data are available from different times. It also looks at the percentage of people who are employed, unemployed or inactive; referring in this instance to the three months ending December 2009. When looking at the employment rates in a time series all data are seasonally adjusted with the exception of lone parents and those living in the most deprived wards. Analysis based solely on data for the three months ending December 2009 are not seasonally adjusted and may result in slight differences in the rates at this time. Unless otherwise stated the analysis is for people under state pension age, covering men aged 16 to 64 and women aged 16 to 59 . Generally for employment, the different groups are presented as rates rather than levels. This is because levels would be affected by changes in population numbers and the groups themselves. Also, because the disadvantaged groups are different sizes comparison of levels between them would be misleading. Data in this article are calculated from the Labour Force Survey (LFS). The LFS is a quarterly sample survey of about 53,000 households living at private addresses in the UK, representing about 0.2 per cent of the population. The survey asks respondents for information on their personal circumstances and labour market status.

Table 1 shows the numbers in each disadvantaged group for the three months ending December 2009 and the percentage of the population this represents. There 
Box 1

\section{Definitions of disadvantaged groups}

Disabled people are those who are currently defined as disabled in accordance with the Disability Discrimination Act (DDA) 1995. This includes people who are DDA disabled only and people who are both DDA disabled and work-limiting disabled.

Lone parents are people of working age caring for a dependent child (a child aged under 16 and those aged 16 to 18 who are never married and in full-time education), who do not have a partner that is a member of the same household.

Ethnic minorities are those who classify themselves to an ethnic background that is non-white.

People aged 50 to state pension age (SPA), that is up to and including aged 64 for men and aged 59 for women.
The lowest qualified are those who have not obtained a minimum of a $C$ grade at GCSE or equivalent. This is different from the PSA definition, which is the 15 per cent lowest qualified, it will give a good indication of the rates in the PSA target.

Those living in the most deprived wards. These wards are the 1250 most deprived in line with the PSA and Department of Work and Pensions methodology. Low level geographical data is not available for Northern Ireland and is therefore the analysis for this group is for Great Britain only.

\section{Table 1}

\section{Level and percentage of people ${ }^{1}$ in disadvantaged groups, October to} December 2009

\begin{tabular}{lrr} 
United Kingdom & \multicolumn{1}{c}{ Not seasonally adjusted } \\
\hline Group & Level (Thousands) & Percentage of population \\
\hline Disabled people & 6,024 & 15.9 \\
Lone parents $^{2}$ & 1,922 & 5.1 \\
Ethnic minorities & 4,417 & 11.6 \\
People aged 50 or over & 9,261 & 24.4 \\
Lowest qualified & 8,466 & 22.3 \\
Those living in the most deprived wards ${ }^{3}$ & 6,896 & 18.7 \\
All people & 37,991 & 100.0 \\
\hline
\end{tabular}

\section{Notes:}

Source: Labour Force Survey

1 People under state pension age; men aged 16 to 64 , women aged 16 to 59

2 This data is from the Labour Force Survey Household dataset.

3 This data is not available for Northern Ireland; therefore this data is for Great Britain.

\section{Figure 1 \\ Employment rate ${ }^{1}$ by disability, April-June 1998 to October-December 2009}

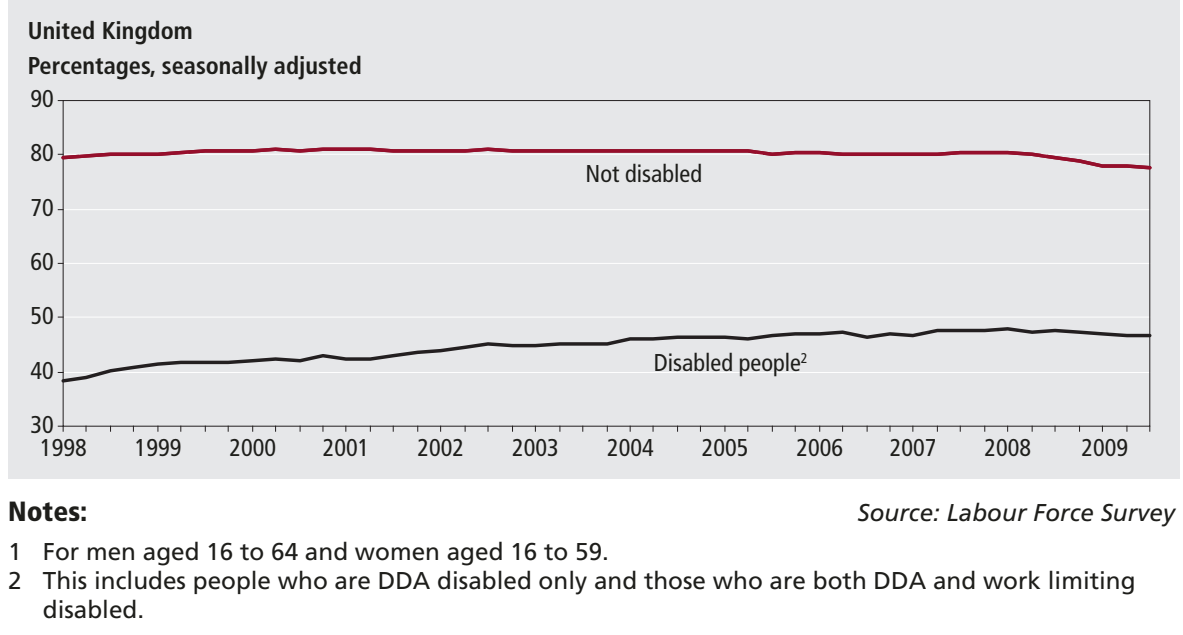

are some individuals in more than one disadvantaged group. Of the 38.0 million people, 9.3 million (24.4 per cent) of them are in the group aged 50 to state pension age, representing the largest of the disadvantaged groups. The smallest disadvantaged group is that consisting of lone parents, representing 1.9 million (5.1 per cent) of people.

\section{Disabled people}

Figure 1 shows the employment rate by disability status for the three months ending June 1998 to the end of 2009. At the start of the series the employment rate for disabled people was 38.3 per cent, around half the employment rate for people who were not disabled, which stood at 79.6 per cent. Over the last decade the employment rate for disabled people has been increasing, and at the end of 2009 it was 46.6 per cent. Over the same period there was very little change in the employment rate for people who were not disabled, with it standing at 77.6 per cent at the end of 2009. This means that over the period there has been a narrowing of the gap, from 41.3 percentage points to 31.0 percentage points, between the employment rates for disabled and not disabled people.

Looking at employment patterns since the start of the 2008/09 recession, employment rates have fallen overall, for all individuals collectively. However, disabled people fared better during the recession with respect to employment rates. Their employment rate fell by 1.2 percentage points, whereas the employment rate for people who were not disabled fell by 2.4 percentage points.

Looking at just employment only considers one of three options for individuals. There are also individuals who are unemployed or economically inactive, with these two groups together representing the total of workless people. Figure 2 shows the percentage of each of these three groups for people who are disabled and not disabled, in the three months ending December 2009. At this time just over half, 53.3 per cent, of disabled people were workless, as opposed to 22.1 per cent of people who were not disabled. The workless percentage comprises mostly of individuals who are economically inactive, 47.8 per cent for disabled, three times that of those not disabled, which stood at 15.9 per cent. 


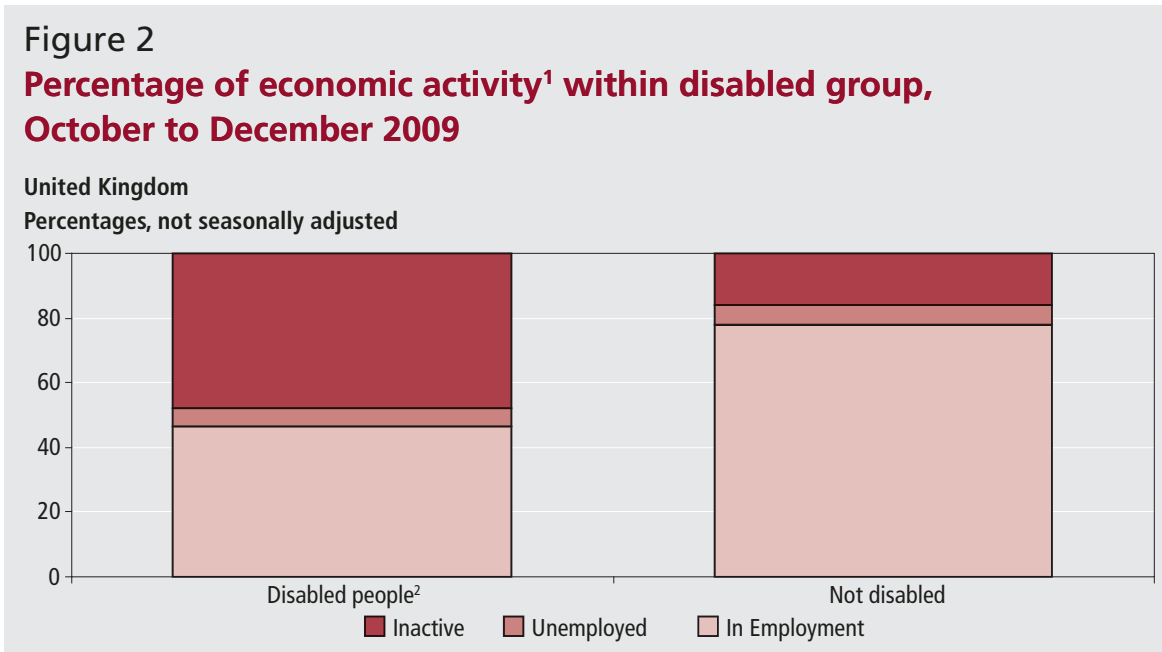

\section{Notes:}

1 For men aged 16 to 64 and women aged 16 to 59 .

2 Those DDA disabled only and those who are both DDA and work limiting disabled.

\section{Figure 3}

\section{Employment rates ${ }^{1}$ by family status, 1997 to $2009^{2}$}

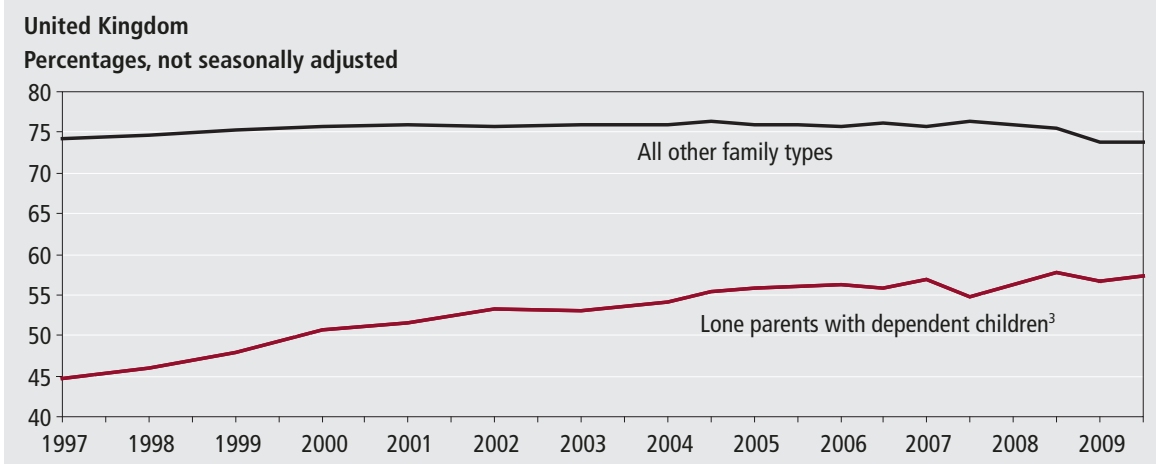

Notes:

1 For men aged 16 to 64 and women aged 16 to 59.

2 April to June quarter, October to December quarter from 2004.

3 Dependent children are those under 16 and those 16 to 18 who are in full time education and have never married.

\section{Figure 4}

\section{Percentage of economic activity ${ }^{1}$ by family type, October to December 2009}

\section{United Kingdom}

Percentages, not seasonally adjusted

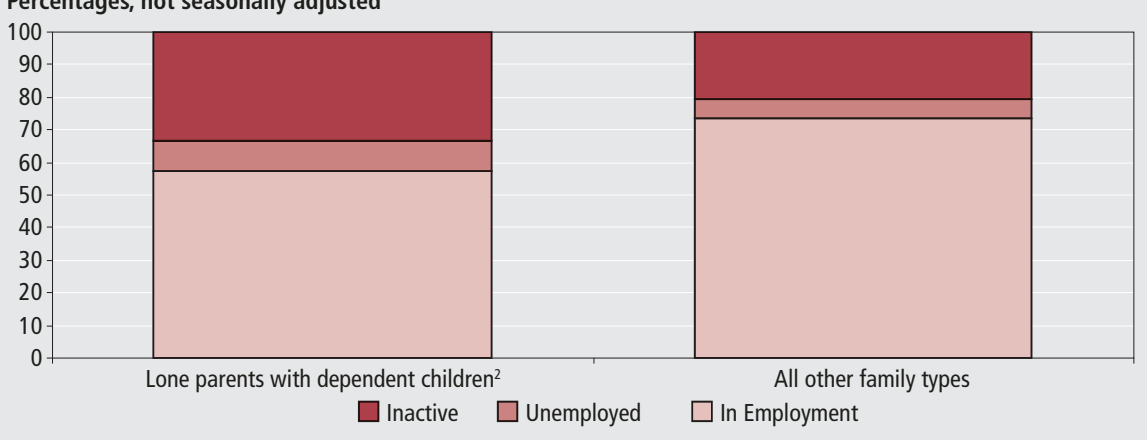

\section{Notes:}

1 For men aged 16 to 64 and women aged 16 to 59

2 Dependent children are those under 16 and those 16 to 18 who are in full time education and have never married.
The main reason for inactivity for the disabled group was being long-term sick or disabled. Looking at unemployment, a smaller percentage of disabled people were unemployed, 5.6 per cent, compared to 6.2 per cent for people who were not disabled.

\section{Lone parents}

Figure 3 shows the employment rate of lone parents when compared with all other family types, such as married and cohabiting parents, those without dependent children and others, for the three months ending June 1997 to the end of 2009 .

At the start of the series, the employment rate for lone parents was 44.6 per cent, and for all other family types, 74.1 per cent. Since this time the employment rate for lone parents has increased and at the end of 2009 it stood at 57.3 per cent. Over the same period there was very little change in the employment rate for all other family types, with it standing at 73.8 per cent at the end of 2009. This means that over the period there has been a narrowing of the gap, from 29.5 percentage points to 16.5 percentage points, between the employment rates for lone parents and all other family types.

Looking at the two groups through the recession to the end of 2009, the employment rate for lone parents increased by 0.9 percentage points, the only disadvantaged group to do so, while for all other family types it fell by 2.2 percentage points.

Figure 4 compares the percentage in each of the three economic status groups, for lone parents and all other family types, for the three months ending December 2009. In this period, around two out of five (42.7 per cent) lone parents were workless, compared to around one in four (26.2 per cent) for all other family types. The majority of the worklessness for both groups is people who are economically inactive, accounting for around one in three lone parents, with the reason given for inactivity being to look after the family or home.

The percentage of people unemployed was larger for lone parents, 9.3 per cent, compared to that of all other family types, 5.9 per cent. This shows that while the gap between the employment rates has narrowed over the last decade, there are a higher percentage of lone parents looking for, and unable to find work, compared to all other family types.

\section{Ethnic minorities}

Figure 5 shows the employment rate by ethnic group for the three months ending 


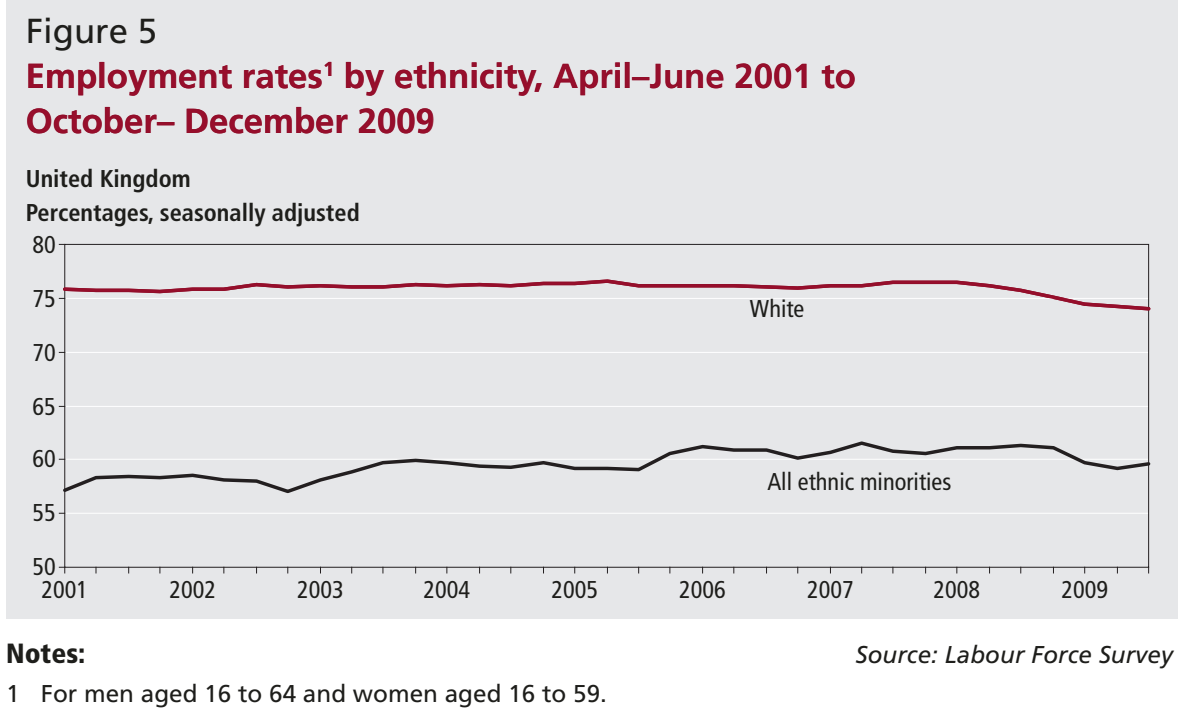

1 For men aged 16 to 64 and women aged 16 to 59 .

Table 2

Percentage of economic activity ${ }^{1}$ within ethnic groups, October to December 2009

\begin{tabular}{lccr} 
United Kingdom & & Per cent, not seasonally adjusted \\
\hline & Employment & Unemployment & Inactivity \\
\hline All ethnic groups & 72.6 & 6.2 & 21.2 \\
White & 74.3 & 5.8 & 19.9 \\
White British $^{2}$ & 74.4 & 5.9 & 19.7 \\
Other White & & 4.8 & 19.5 \\
All ethnic minority groups & 75.7 & 9.2 & 30.9 \\
Mixed & 59.9 & 10.1 & 28.4 \\
Asian or Asian British & 61.5 & 7.9 & 31.7 \\
Indian & 60.4 & 6.4 & 22.7 \\
Pakistani & 70.9 & 10.0 & 43.5 \\
Bangladeshi & 46.5 & 10.8 & 44.5 \\
Other Asian & 44.7 & 6.6 & 27.0 \\
Black or Black British & 66.4 & 13.2 & 27.6 \\
Black Caribbean & 59.2 & 13.5 & 21.2 \\
Black African & 65.3 & 12.3 & 32.5 \\
Other Black & 55.2 & 21.0 & 25.6 \\
Other including Chinese & 53.4 & 7.0 & 34.1 \\
\hline
\end{tabular}

\section{Notes:}

Source: Labour Force Survey

1 For men aged 16 to 64 and women aged 16 to 59 .

2 These data are presented for Great Britain only and exclude Northern Ireland.

\section{Figure 6 \\ Employment rates ${ }^{1}$ by age group, January-March 1995 to October-December 2009}

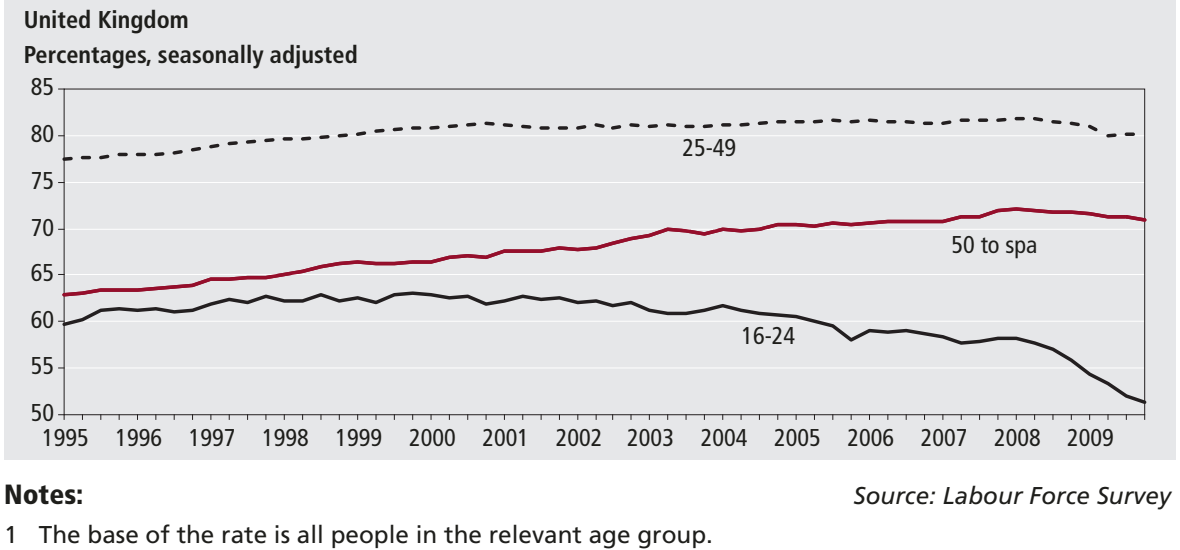

June 2001 to the end of 2009. At the start of the series the employment rate of ethnic minority groups was 57.2 per cent, 18.6 percentage points lower than the employment rate for the white group, which stood at 75.8 per cent.

The employment rate for the ethnic minorities group has been consistency lower than the rate for white people. However, the employment rate for ethnic minority groups has been increasing and by the end of 2009 it stood at 59.6 per cent. Over the same period, the employment rate for white people has remained fairly constant, standing at 74.0 per cent at the end of 2009. Therefore there has been a narrowing in the gap between the employment rates for the two groups, from 18.6 percentage points, to 14.5 percentage points at the end of 2009.

During the recession the employment rate for both groups has fallen, with a slightly smaller fall for ethnic minority groups, of 1.9 percentage points, compared to white people, of 2.2 percentage points.

The economic status of individuals differs greatly among the various ethnic minority groups. Table 2 shows the percentage employed, unemployed and inactive, for the three months ending December 2009. Of the ethnic minority groups, the Indian group had the highest percentage employed at 70.9 per cent. The lowest percentages of employment were for the Bangladeshi and Pakistani groups, being 44.7 per cent and 46.5 per cent respectively. The main reason for such a small percentage of people employed in these groups is that there are a large percentage of people inactive. For the Bangladeshi ethnic group, the percentage inactive stood at 44.5 per cent, and for the Pakistani group, 43.5 per cent. The main reason for inactivity in these groups was to look after the family or home.

The ethnic minority groups have a higher percentage of people unemployed, 9.2 per cent, compared to 5.8 per cent for white people. Of the ethnic minority groups the Indian and Other Asian groups had the lowest percentage unemployed, 6.4 per cent and 6.6 per cent respectively, still higher than that for white people. The highest percentage is for the Other Black group, 21.0 per cent, although the sample size for this group is relatively small and therefore subject to higher sampling variability.

\section{People aged 50 to state pension} age

Figure $\mathbf{6}$ shows employment rates of age groups for the three months ending March 1995 to the end of 2009. Due to a large fall 
Figure 7

Economic activity within age group, October to December 2009

United Kingdom

Percentages, not seasonally adjusted

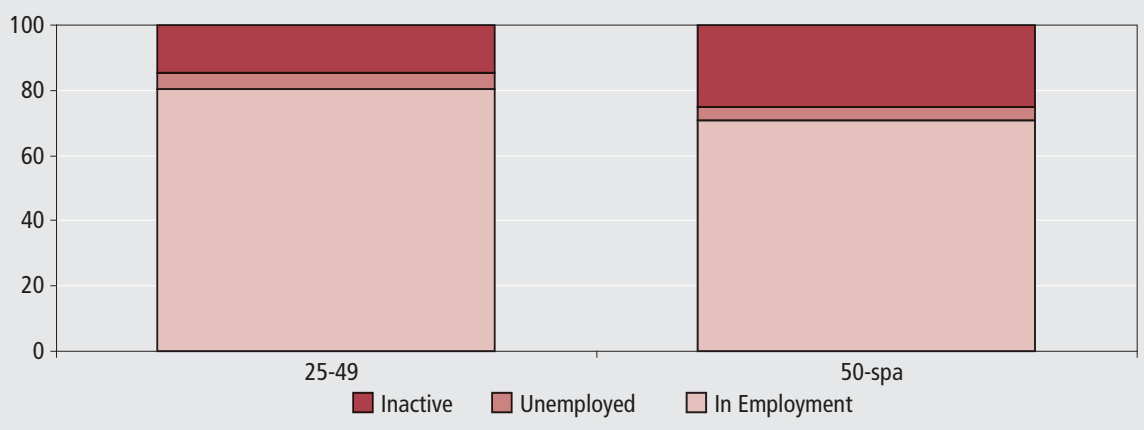

Source: Labour Force Survey

\section{Figure 8 \\ Employment rates ${ }^{1}$ by qualification, January-March 1995 to October-December 2009}

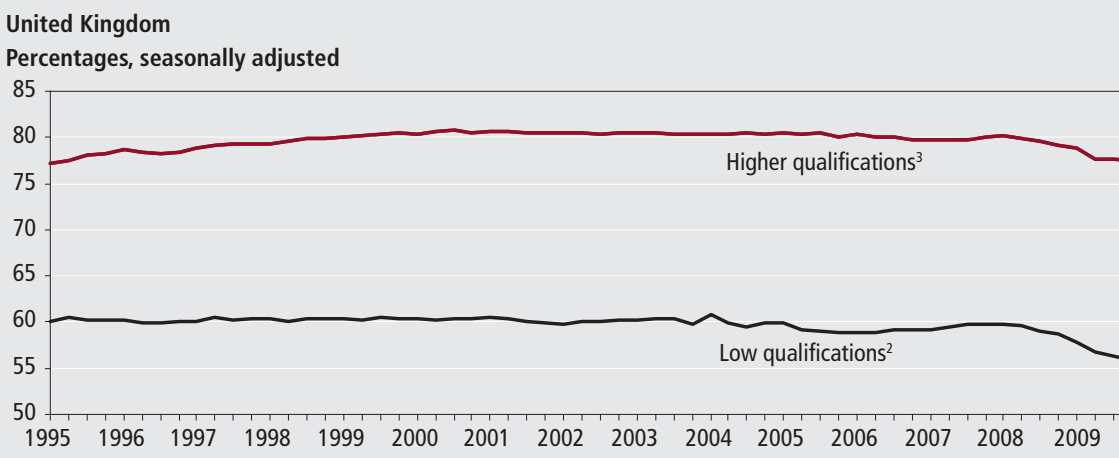

Notes:

Source: Labour Force Survey

1 For men aged 16-64 and women aged 16-59.

2 Less than GCSE grade $A$ * to $C$ or equivalent.

3 GCSE grade $A$ * to $C$ or equivalent and higher.

in the employment rates for people aged 16 to 24 over the last six to seven years, partly through policies aimed at keeping this group in education, people aged 50 to state pension age (SPA) will be compared to people aged 25 to 49 .

At the start of the series, the employment rate for people age aged 50 to SPA was 62.9 per cent, 14.6 percentage points lower than the rate for people aged 25 to 49 , which stood at 77.5 per cent. Throughout the series, the employment rate for people age 50 to SPA has been generally increasing, and was 71.0 per cent by the end of 2009 . The employment rate has also increased, but less quickly, for people aged 25 to 49 , standing at 80.2 per cent at the end of 2009 . Therefore, there has been a narrowing in the gap between the employment rates of these two groups, from 14.6 percentage points, to 9.2 percentage points at the end of 2009 .

Looking at employment from the start of the recession to the end of 2009, the rates for both people aged 50 to SPA and those aged 25 to 49 both fell. However, the employment rate for people aged 50 to SPA fell by 0.6 percentage points, a third of the fall in the rate for people aged 25 to 49 , which was 1.8 percentage points.

Figure 7 shows the percentage of people employed, unemployed and economically inactive for the age groups 25 to 49 and aged 50 to SPA, for the three months ending December 2009. At this time around three to SPA were workless, as opposed to 19.7

The workless comprise mostly of individuals who are economically inactive, 25.2 per cent for people aged 50 to SPA, compared to 14.5 per cent of people aged 25 to 49 . The main reason for inactivity for people aged 50 to spa was being long-term sick or disabled. Looking at unemployment, a smaller percentage of people aged 50 to SPA were unemployed, 3.8 per cent, compared to 5.2 per cent for people aged 25 to 49 .

\section{The lowest qualified}

Figure 8 shows the employment rate for people with low or no qualifications and out of ten, 29.0 per cent, of people aged 50 per cent of people who were aged 25 to 49 . those with all other qualifications for the three months ending March 1995 to the end of 2009. At the start of the series the employment rate for people with low or no qualifications stood at 60.1 per cent, 17.0 percentage points lower than the rate for people with higher qualifications, which was 77.2 per cent. Since then, the rate remained fairly constant until the start of the 2008/09 recession when it began to decrease, much more than that of the other disadvantaged groups considered in this article, to stand at 55.8 per cent at the end of 2009. Over the same period the employment rate for people with all other qualifications increased slightly until the start of the recession, after which it decreased, to stand at 77.4 per cent at the end of 2009. Because of this there has been an increase in the gap between people who have low or no qualifications and those with higher qualifications, from 17.0 percentage points at the start of 1995 , to 21.6 percentage points at the end of 2009.

However, individuals have a choice when it comes to qualifications, in that they can develop new skills to improve their qualification levels. At the start of the series in 1995, 36.6 per cent of people held low or no qualifications. At the end of 2009 this had decreased and 22.7 per cent of people were in this group. Therefore, while the gap between the employment rate between those with low or no qualifications has widened to that with higher qualifications, a higher percentage of people are in the latter group.

Figure 9 compares the percentage in each of the three economic status groups, for those with low or no qualifications, and those with higher qualifications. A higher percentage of people are inactive in the low or no qualifications group, 35.0 per cent, compared to those with higher qualifications, 17.1 per cent. The main reason for this difference is more individuals inactive due to being longterm sick or disabled in the low or no qualifications group.

There are also a higher percentage of people in the low or no qualifications group who are unemployed, 8.6 per cent, compared to those with higher qualifications, 5.5 per cent. With lower skills than their higher qualified counterparts, it would be more difficult in a fair and open competition, for those with no or low qualifications to obtain employment. Combining both those people that are inactive and unemployed shows that the percentage of people who are workless (43.6 per cent) for low or no qualifications 


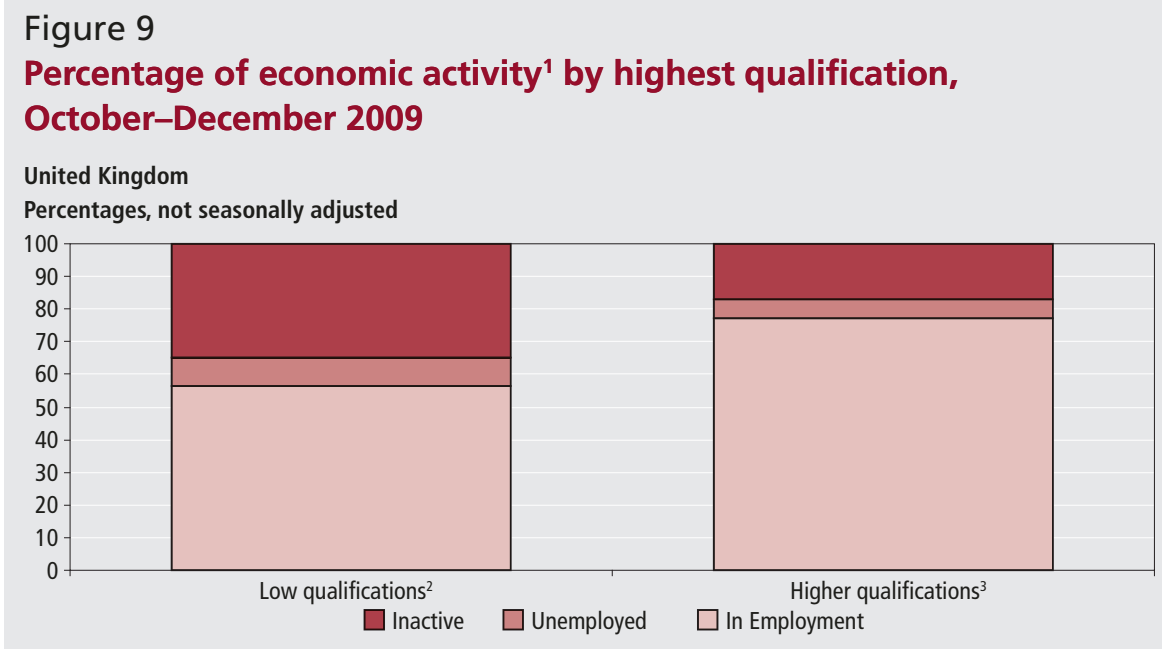

Notes:

1 For men aged 16-64 and women aged 16-59.

2 Less than GCSE grade $A^{*}$ to $C$ or equivalent.

3 GCSE grade $A *$ to $C$ or equivalent and higher.

\section{Figure 10 \\ Employment rates ${ }^{1}$ of those living in the most deprived wards, October-December 2003 to October-December 2009}

Great Britain

Percentages, not seasonally adjusted

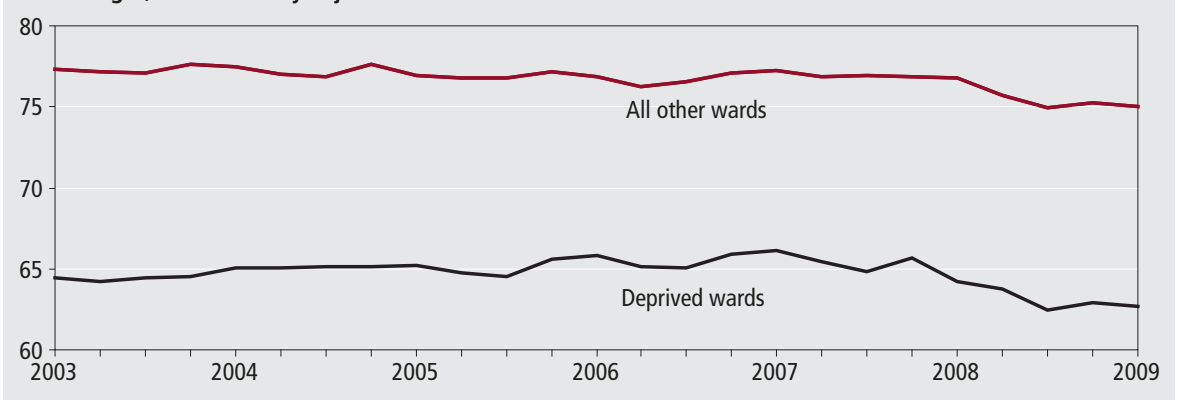

Notes:

Source: Labour Force Survey

1 For men aged 16 to 64 , women aged 16 to 59 .

is almost double that for those with higher qualifications (22.6 per cent).

\section{Those living in the most deprived wards}

Figure 10 shows the employment rate of those living in the most deprived wards, compared to all other wards, in Great Britain for the three months ending December 2003 to the three months ending December 2009. Local level area data is not available for Northern Ireland; therefore analysis is restricted to Great Britain. Care should be taken when looking at a longterm time series of deprived wards as some of the wards may not have been classified as deprived previously.

At the start of the series the employment rate for those living in the most deprived wards was 64.5 per cent, 12.9 percentage points less than the employment rate for all other wards, which stood at 77.3 per cent. The employment rate was relatively stable for all others of 75.0 per cent. Noting that for this series, the time frame is much shorter, there has been little change in the gap, compared to that of some of the other disadvantaged groups, between the most deprived and other wards. At the end of 2009, the gap stood at 12.3 percentage points, 0.5 percentage points less than the start of the series, with part of this gap, 0.2 percentage points, occurring since the start of the recession.

Figure 11 compares the percentage in each of the three economic status groups, for those living in the most deprived wards and all others, in the three months ending December 2009. Over a third of people living in the most disadvantaged wards were workless, 37.3 per cent, compared to a quarter, 25.0 per cent, of people living in other wards. As with the other disadvantaged groups, most of the workless people are in the inactive group, with 28.4 per cent falling in this group for the most deprived wards, compared to 19.3 per cent for all other wards. The main reason for people being inactive in deprived wards is being long term sick or disabled. Of those unemployed, the percentage of people living in the most deprived wards who were unemployed was 9.0 per cent, compared to 5.6 per cent for those in other wards.

\section{Multiple disadvantaged groups}

So far this article has looked at the disadvantaged groups individually. However the groups are not mutually exclusive as an individual could belong to any number of groups, so it is worth looking at the groups in combination. Due to the restrictions on the analysis of disadvantaged wards, this section on multiple disadvantaged groups is for Great Britain only, excluding Northern Ireland.

Table 3 shows the number of individuals

\section{Figure 11 \\ Percentage of economic activity of those living in the most deprived wards, October to December 2009}

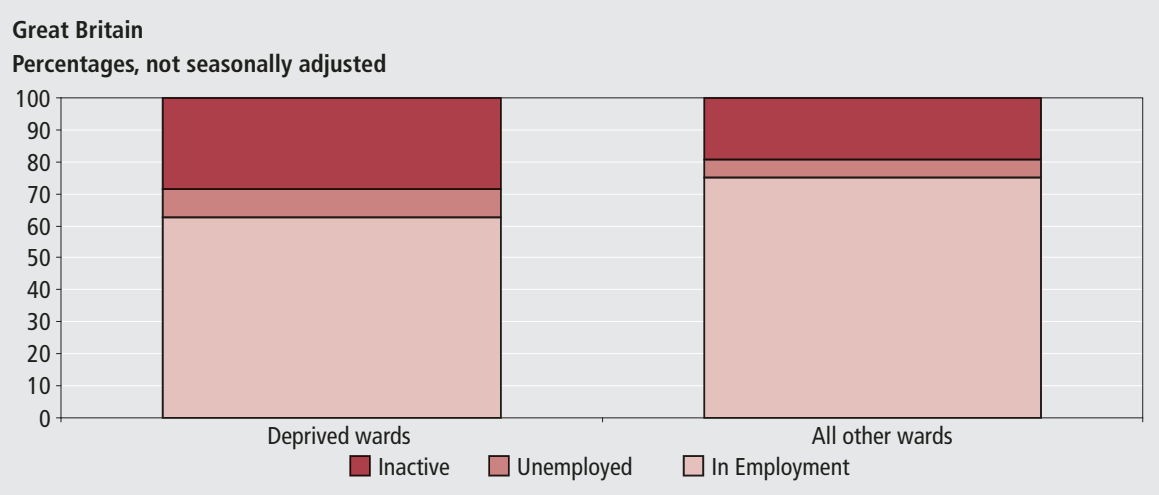

Source: Labour Force Survey 
Table 3

Level and percentage by number of disadvantaged groups to which a person belongs, ${ }^{1}$ October to December 2009

Great Britain

Not seasonally adjusted

Number of groups

Level (Thousands)

Percentages

\begin{tabular}{lrr}
0 & 14,234 & 38.6 \\
1 & 12,736 & 34.5 \\
2 & 6,714 & 18.2 \\
3 & 2,551 & 6.9 \\
4 & 599 & 1.6 \\
5 or 6 & 60 & 0.2 \\
Total & 36,894 & 100.0 \\
\hline
\end{tabular}

\section{Notes:}

Source: Labour Force Survey

1 For men aged 16 to 64 and women aged 16 to 59 .

Table 4

Percentage of economic activity ${ }^{1}$ by number of disadvantaged groups to which a person belongs, October to December 2009

\begin{tabular}{lccc} 
Great Britain & \multicolumn{2}{c}{ Per cent, not seasonally adjusted } \\
\hline Number of groups & In employment & Unemployed & Inactive \\
\hline 0 & 82.6 & 5.1 & 12.3 \\
1 & 75.4 & 6.8 & 17.8 \\
2 & 62.4 & 7.2 & 30.4 \\
3 & 42.9 & 8.0 & 49.2 \\
4 & 28.2 & 6.2 & 65.6 \\
5 or 6 & 14.5 & 8.2 & 77.3 \\
Total & 72.7 & 6.3 & 21.0 \\
\hline
\end{tabular}

Notes:

Source: Labour Force Survey

1 For men aged 16 to 64 and women aged 16 to 59.

and how many disadvantaged groups they belong, along with the percentage this represents. Overall there are 22.7 million people in at least one disadvantaged group, representing around three out of five people (61.4 per cent). Of those in a disadvantaged group, there are 12.7 million in one group, 6.7 million in two groups, 2.5 million in three groups, 599,000 in four groups and 60,000 in at least five of the groups.

Table 4 shows the percentage in each of the three economic status groups and how these differ by the number of disadvantaged groups a person belongs, in the three months ending December 2009. As the number of disadvantaged groups an individual is in increases, the percentage employed decreases. as the other two economic groups, from 5.1 per cent for those in no disadvantaged group, to 8.2 per cent for those in five or six disadvantaged groups. This shows that as the number of disadvantaged groups to which a person belongs increases, they are more likely to become inactive, rather than unemployed.

\section{Conclusion}

This article has shown that around three in five people aged under state pension age are identified as being in one of the disadvantaged groups when looking at their labour market prospects. It has shown that for nearly all of the groups, there has been a narrowing of the employment rate of the disadvantaged group, when compared to all others in the population, with the exception of those with low or no qualifications. However, over the last fifteen years, the percentage of people in the population with low or no qualifications has decreased. Of the disadvantaged groups, lone parents have had the largest narrowing of employment rates compared to others, and was the only group to have seen an increase in employment rate through the recent recession.

Where the employment rate is lower for people in the disadvantaged groups, compared to others in the population, most of the difference is for people who are inactive. However, the reason for being inactive differs across the disadvantaged groups, with lone parents and some of the ethnic minority groups having their main reason as looking after the family or home. This compares with those disabled, aged 50 and over, with low or no qualifications or in deprived areas having their main reason for inactivity as being long term sick or disabled.

\section{CONTACT}

四elmr@ons.gov.uk 